\title{
Controlling the Shape of Molecular Weight Distributions in Coordination Polymerization and Its Impact on Physical Properties
}

\author{
Renee J. Sifri, Omar Padilla-Vélez, Geoffrey W. Coates, ${ }^{*}$ and Brett P. Fors* \\ Department of Chemistry and Chemical Biology, Baker Laboratory, Cornell University, \\ Ithaca, New York 14853-1301, United States
}

$\begin{array}{ll}\text { I. General Considerations } & \text { S2 }\end{array}$

$\begin{array}{ll}\text { II. Materials } & \text { S3 }\end{array}$

$\begin{array}{ll}\text { III. Ethylene Polymerizations } & \text { S3 }\end{array}$

$\begin{array}{lr}\text { IV. Differential Scanning Calorimetry Measurements } & \text { S8 }\end{array}$

$\begin{array}{lr}\text { V. Gel Permeation Chromatograms } & \text { S9 }\end{array}$

VI. Calculation of Asymmetry Factors and Skewness $\quad$ S11

$\begin{array}{ll}\text { VII. Rheological Measurements } & \text { S13 }\end{array}$

$\begin{array}{ll}\text { VIII. Uniaxial Tensile Tests } & \text { S16 }\end{array}$

$\begin{array}{lr}\text { IX. References } & \text { S19 }\end{array}$ 


\section{General Considerations}

Air and/or moisture sensitive compounds were manipulated under nitrogen atmosphere using standard Schlenk techniques or in an MBraun Unilab glovebox. Molecular weights $\left(M_{\mathrm{n}}\right.$ and $\left.M_{\mathrm{w}}\right)$ and dispersities $(\bigoplus)$ were determined by gel permeation chromatography (GPC). Analyses were performed using an Agilent PL-220 GPC equipped with an RI detector. The column set (three Agilent PL-Gel Mixed B columns and one PL-Gel Mixed B guard column) was eluted with 1,2,4trichlorobenzene containing $0.01 \mathrm{wt} \%$ of 3,5-di-tert-butyl-4-hydroxytoluene (BHT) at $1.0 \mathrm{~mL} / \mathrm{min}$ at $150{ }^{\circ} \mathrm{C}$. Data were measured relative to a polyethylene calibration curve (Varian and Polymer Standards Service). Peak polymer melting temperatures $\left(T_{\mathrm{m}}\right)$ were measured by differential scanning calorimetry (DSC) using a Mettler Polymer DSC calorimeter equipped with an autosampler. Analyses were performed in aluminum pans under nitrogen and data were collected from the second heating run at a heating rate of $10{ }^{\circ} \mathrm{C} / \mathrm{min}$ from $0{ }^{\circ} \mathrm{C}$ to $200{ }^{\circ} \mathrm{C}$ and cooled from $200{ }^{\circ} \mathrm{C}$ to $0{ }^{\circ} \mathrm{C}$ at a cooling rate of $10{ }^{\circ} \mathrm{C} / \mathrm{min}$. The ${ }^{1} \mathrm{H} \mathrm{NMR},{ }^{13} \mathrm{C}\left\{{ }^{1} \mathrm{H}\right\} \mathrm{NMR}$ and ${ }^{19} \mathrm{~F}\left\{{ }^{13} \mathrm{C}\right\} \mathrm{NMR}$ spectra were recorded on a Bruker AV III HD spectrometer with a broad band Prodigy cryoprobe $\left(\left({ }^{1} \mathrm{H}, 500 \mathrm{MHz}\right),\left({ }^{13} \mathrm{C}, 126 \mathrm{MHz}\right)\right)$ at $22{ }^{\circ} \mathrm{C}$ and were referenced to the residual solvent signal $\left[\mathrm{CDCl}_{3}: 7.26 \mathrm{ppm}\left({ }^{1} \mathrm{H}\right), 77.16 \mathrm{ppm}\left({ }^{13} \mathrm{C}\right)\right]$.

Rheological characterization was conducted on a controlled stress TA Instruments DHR3 rheometer with an $8 \mathrm{~mm}$ parallel plate geometry and environmental test chamber for temperature control. Uniaxial tensile elongation was carried out using a Shimadzu Autograph AGS-X tensile tester. Melt compression molding was carried out using a 4120 Hydraulic Unit Carver Press and stainless-steel molds. Mylar protective sheets were obtained from Carver. All polymer processing was carried out on pristine materials (i.e., no BHT, other anti-oxidants, or additives were added). Further experimental details are provided in the appropriate sections below. 


\section{Materials}

Toluene was vigorously sparged with nitrogen for 45 minutes and purified over columns of 4 $\AA ̊$ molecular sieves and copper (Q5) and degassed via three freeze-pump-thaw cycles prior to use. Ethylene (Matheson, ultra-high purity 99.95\%) was purified over columns of copper (Q5) and $4 \AA$ molecular sieves. Methanol (Fisher Chemical) and $\mathrm{HCl}$ (EMD Millipore Corporation) were purchased and used as received. Methylaluminoxane (MAO) was generously donated by the Albemarle Corporation (30 wt\% in toluene) and dried by removing volatiles (toluene and trace trimethylaluminum) under vacuum and heating at $40{ }^{\circ} \mathrm{C}$ for at least 8 hours. Complex 1 was prepared according to the reported literature procedure and its characterization data matched literature reports. ${ }^{1}$

\section{Ethylene Polymerizations}

\section{A. General Procedure}

All polymerizations were set up in an MBraun Unilab glovebox. In a typical reaction, an ovendried $500 \mathrm{~mL}$ Fisher-Porter bottle (Andrews Glass) equipped with a magnetic stir bar was charged with dried MAO (144 mg, $2.50 \mathrm{mmol}$ of Al) and toluene $(200 \mathrm{~mL})$. The vessel was sealed with a Swagelok reactor head (Figure S1). A solution of the initiator (1) (10.0 mg, $12.3 \mu \mathrm{mol})$ in toluene $(15 \mathrm{~mL})$ was prepared and drawn into a $20 \mathrm{~mL}$ HSW Norm-Ject syringe equipped with a stainlesssteel needle (Hamilton, 12 inch, gauge 18, point style 2), which was sealed at the tip using a rubber septum. The reactor and syringe were then removed from the glovebox. The reactor was submerged into a $23{ }^{\circ} \mathrm{C}$ water bath and ethylene was charged into the reactor at 8 psig for $40 \mathrm{~min}$ with vigorous stirring to saturate the solution with $c a .660 \mathrm{mg}$ of ethylene. The reactor weight was recorded before and after addition of ethylene. The syringe containing the initiator then was mounted onto a New Era NE-4000 Double Syringe Pump, which was programmed with the appropriate addition rate profile (see details below). The syringe needle was introduced into the reactor through a neoprene core Pete's plug (Petersen Products). Immediately after manually adding one drop of the initiator solution, the syringe pump addition profile was started. The reaction mixture was quenched with methanol $(10 \mathrm{~mL})$ while stirring when the pressure gauge on the Swagelok reactor head reached 0.4 psig. The polymer solution was precipitated into acidic methanol $(25 \mathrm{~mL}$ of $37 \% \mathrm{HCl}$ in $475 \mathrm{~mL}$ of methanol) and stirred for at least $4 \mathrm{~h}$. The resulting polymers were filtered, washed with methanol and dried under vacuum at $60^{\circ} \mathrm{C}$ to constant weight. 


\section{B. Syringe Pump Addition Rate Profiles}

The synthesis was performed according to the general procedure with the New Era NE-4000 Double Syringe Pump programmed to the following addition rate profiles (Table S1-S2). Polymer sample P1 (Figure 2) was made by adding $10 \mathrm{~mL}$ of the initiator solution at the allowed maximum rate $(57.99 \mathrm{~mL} / \mathrm{min})$.

Table S1. Constant addition rate profiles used for producing polymers P1-P6 (Figure 2).

\begin{tabular}{ccccc}
\hline $\begin{array}{c}\text { Polymer } \\
\text { Sample }\end{array}$ & $\begin{array}{c}\text { Addition Time } \\
(\mathrm{min})\end{array}$ & $\begin{array}{c}\text { Rate } \\
(\mathrm{mL} / \mathrm{min})\end{array}$ & $\begin{array}{c}\text { Total Volume of Initiator } \\
\text { Solution }(\mathrm{mL})\end{array}$ & $\begin{array}{c}\text { Total Reaction } \\
\text { Time (min) }\end{array}$ \\
\hline P1 & 0.2 & 57.99 & 10 & 66 \\
P2 & 20 & 0.50 & 10 & 52 \\
P3 & 30 & 0.33 & 10 & 82 \\
P4 & 40 & 0.25 & 10 & 92 \\
P5 & 50 & 0.20 & 10 & 94 \\
P6 & 60 & 0.17 & 10 & 118
\end{tabular}


Table S2. Exponential addition rate profiles used for producing polymers P7-P11 (Figure 2). All exponential addition rate profiles were programmed as a sequence of 20 step increments with each step corresponding to a phase in the New Era NE-4000 Double Syringe Pump for a total addition volume of $10 \mathrm{~mL}$.

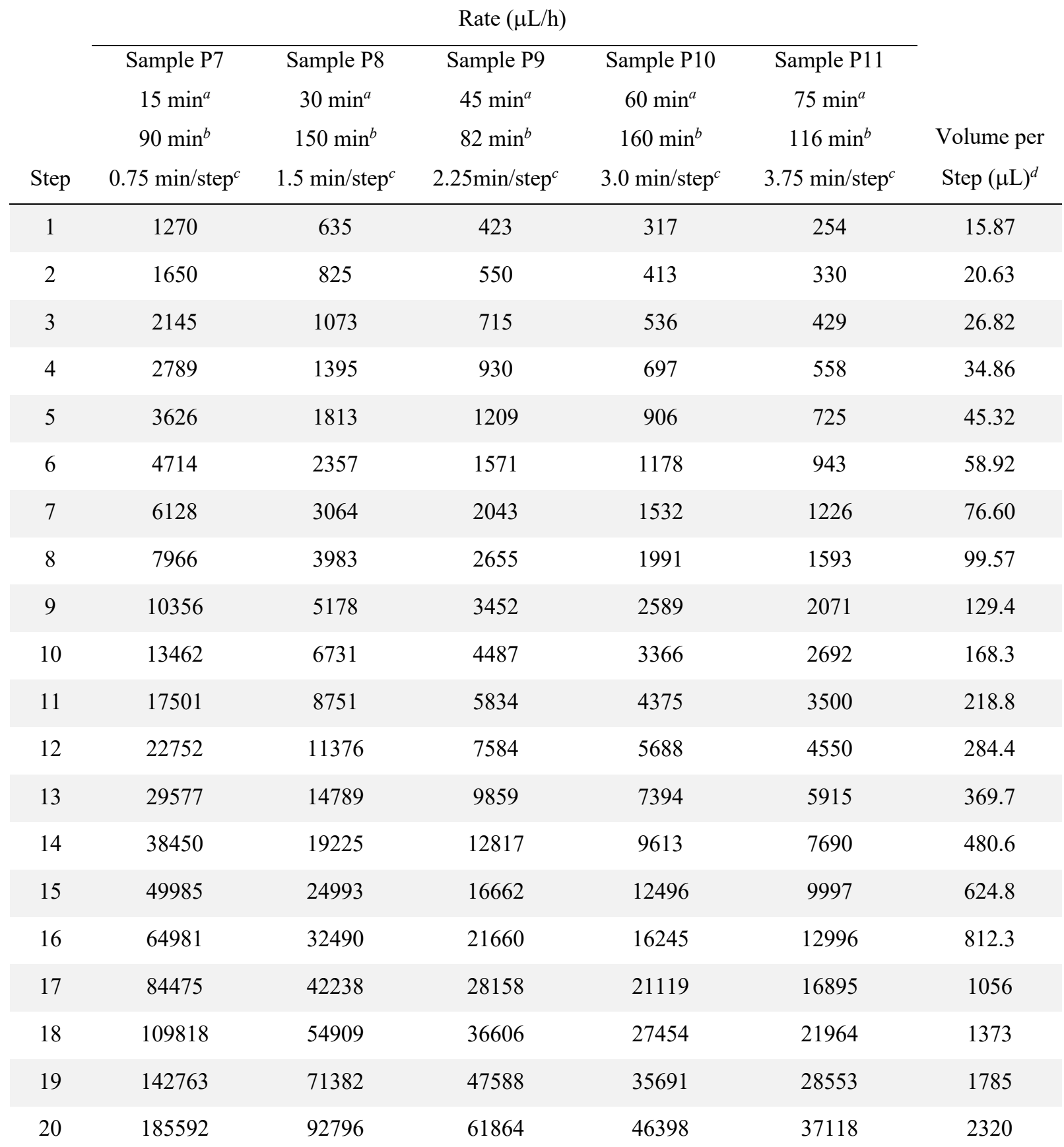

${ }^{a}$ Initiator addition time. ${ }^{b}$ Total reaction time. ${ }^{c}$ Addition time per step. ${ }^{d}$ Volume programmed into syringe pump, average drop size is $8 \mu \mathrm{L}$. 


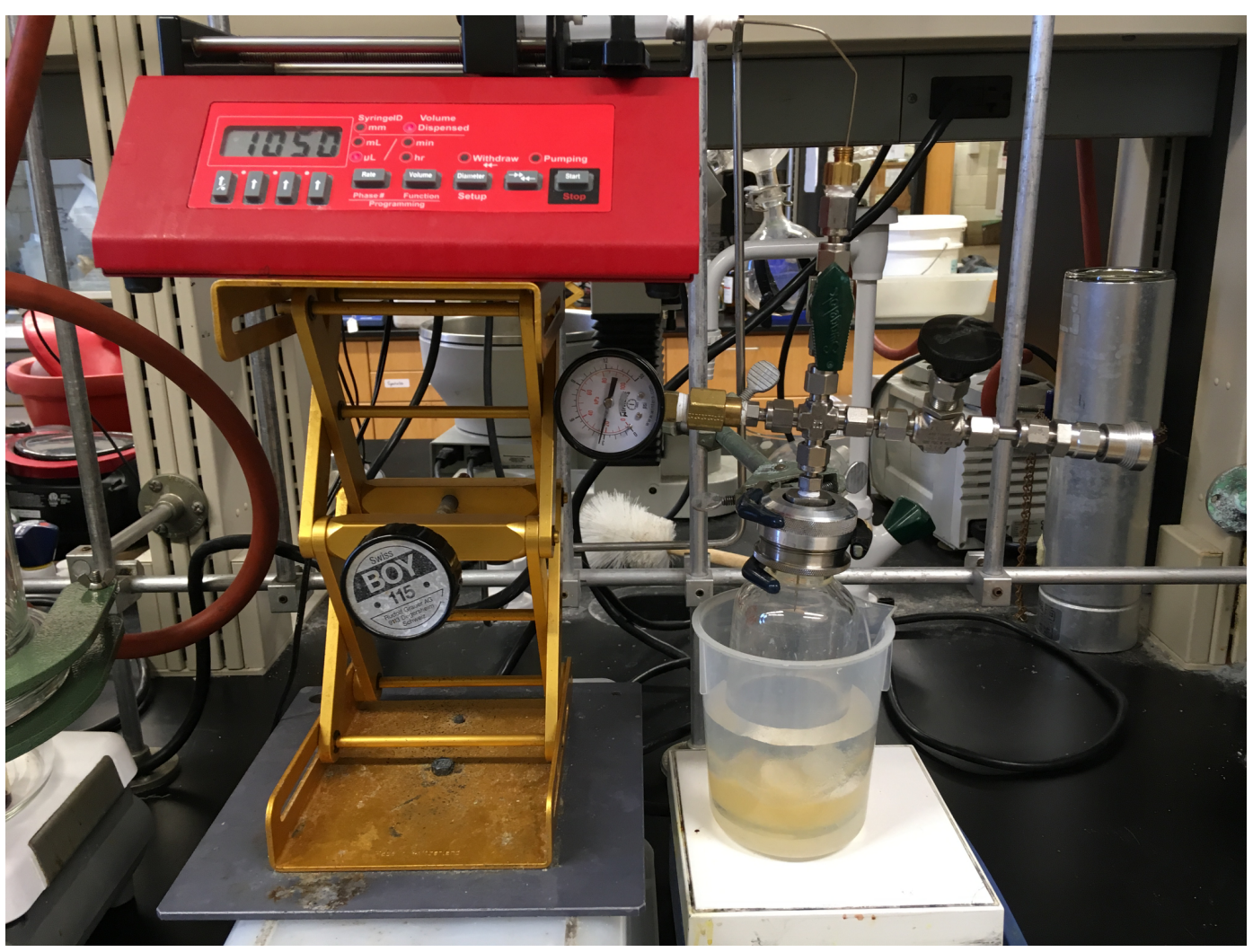

Figure S1. Image of ethylene polymerization reactor and syringe pump setup. 

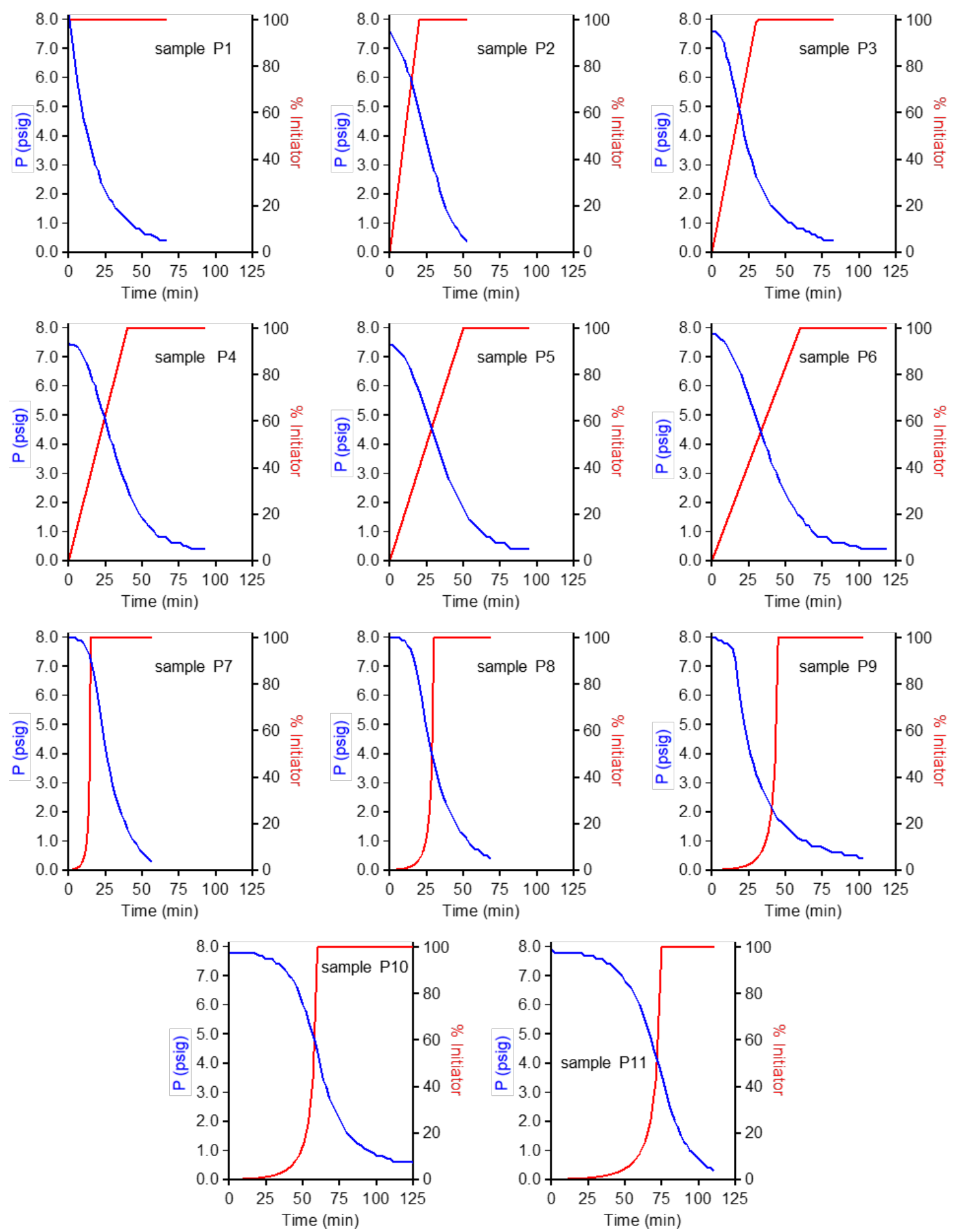

Figure S2. Polymerization progress of the polymer samples in Figure 2 as measured by ethylene consumption (monitored using pressure gauge on the Swagelok reactor head) (blue trace) and percent of total initiator present in the reaction at a given time based on the addition rate profile used (red trace). All polymerizations were quenched with methanol when the pressure gauge on the reactor head read 0.4 psig. 


\section{Differential Scanning Calorimetry Measurements}

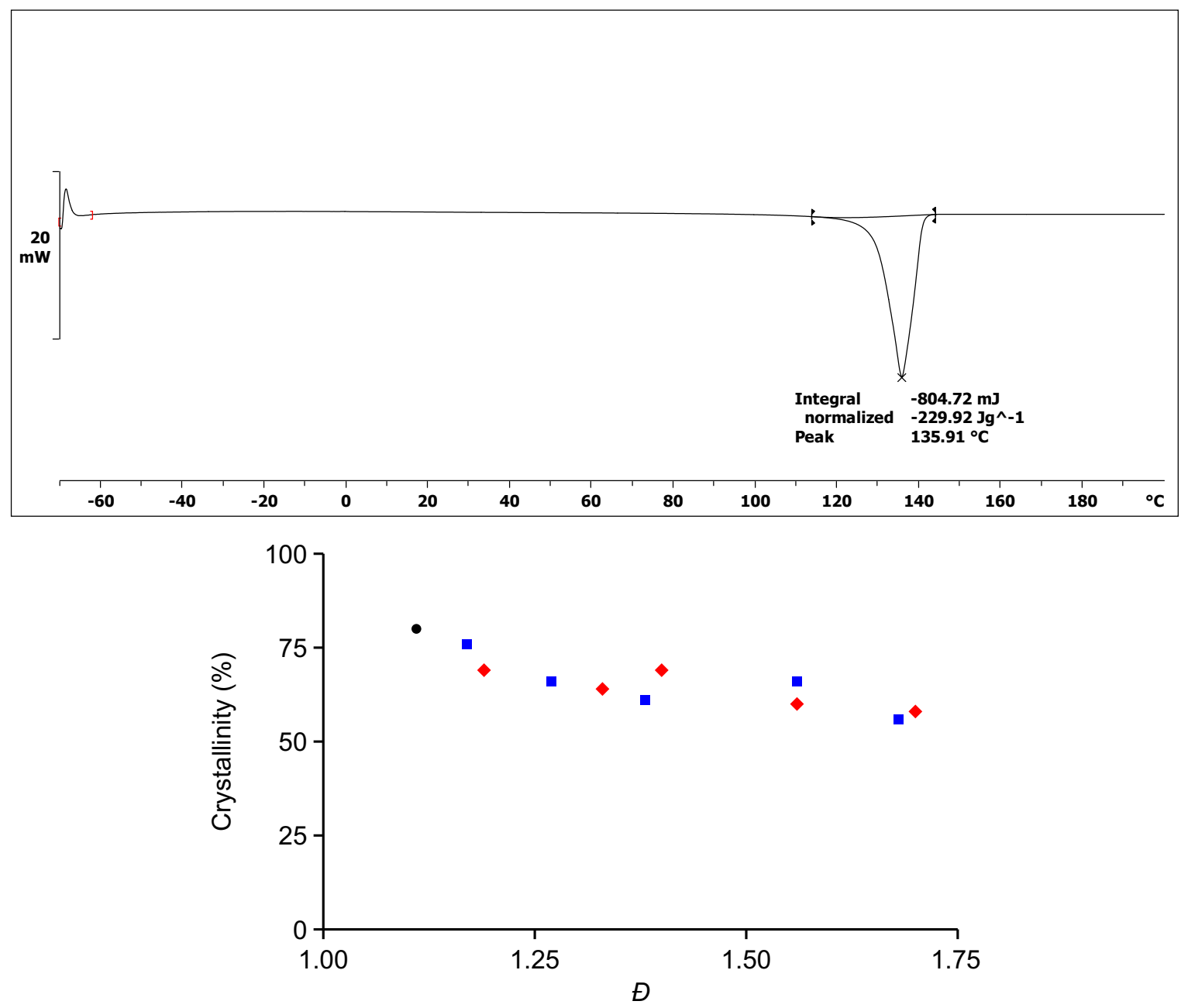

Figure S3. Differential scanning calorimetry (DSC) trace of LPE sample P1 (top) and plot of percent crystallinity vs $\oslash$ for all polymer samples (bottom). Data obtained from the second heating cycle, measurements were conducted between -70 and $200{ }^{\circ} \mathrm{C}$ at $10^{\circ} \mathrm{C} / \mathrm{min}$. 


\section{Gel Permeation Chromatograms}
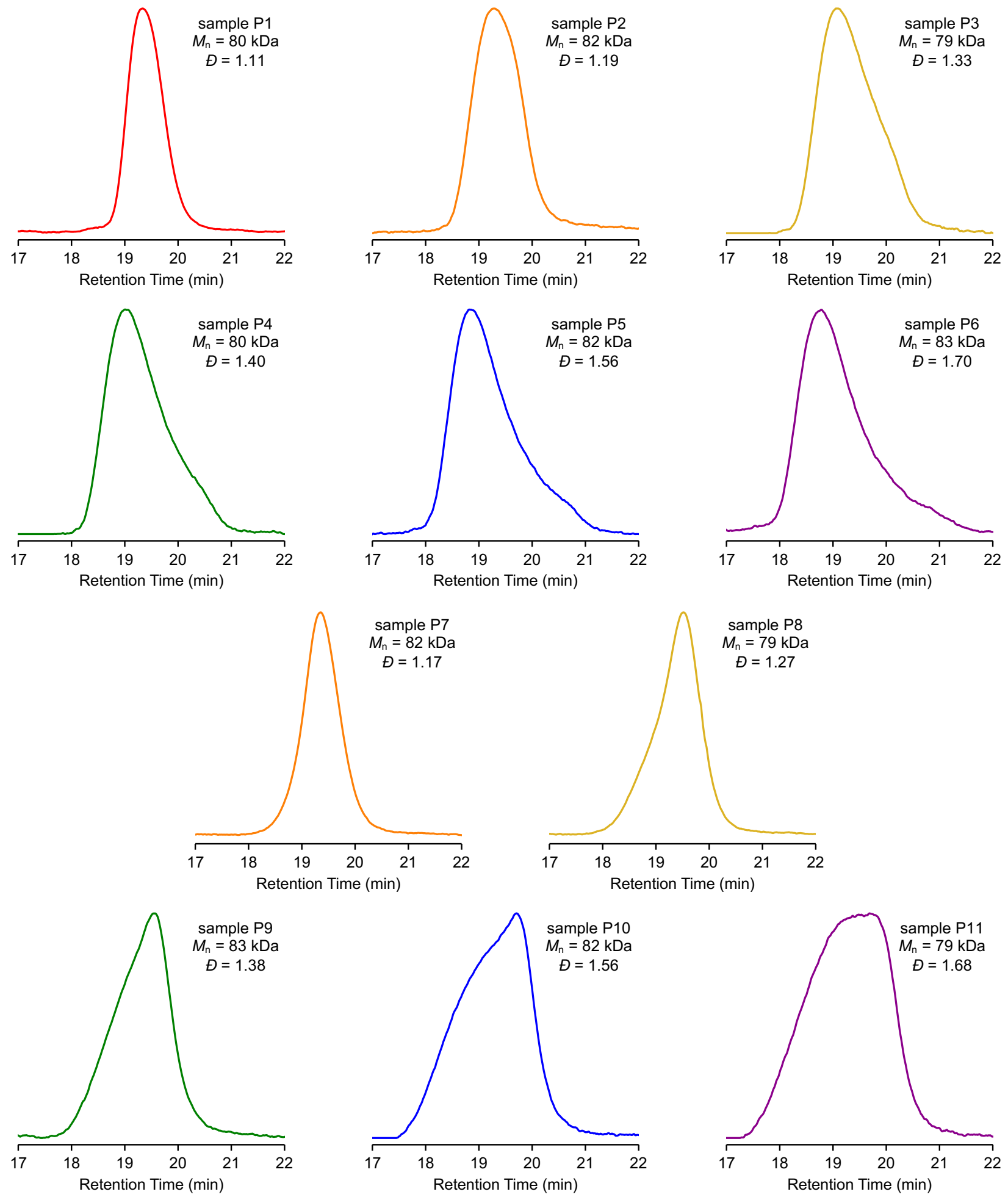

Figure S4. Gel permeation chromatograms of the polymer samples in Figure 2 determined in 1,2,4trichlorobenzene at $150{ }^{\circ} \mathrm{C}$ calibrated with polyethylene standards. 

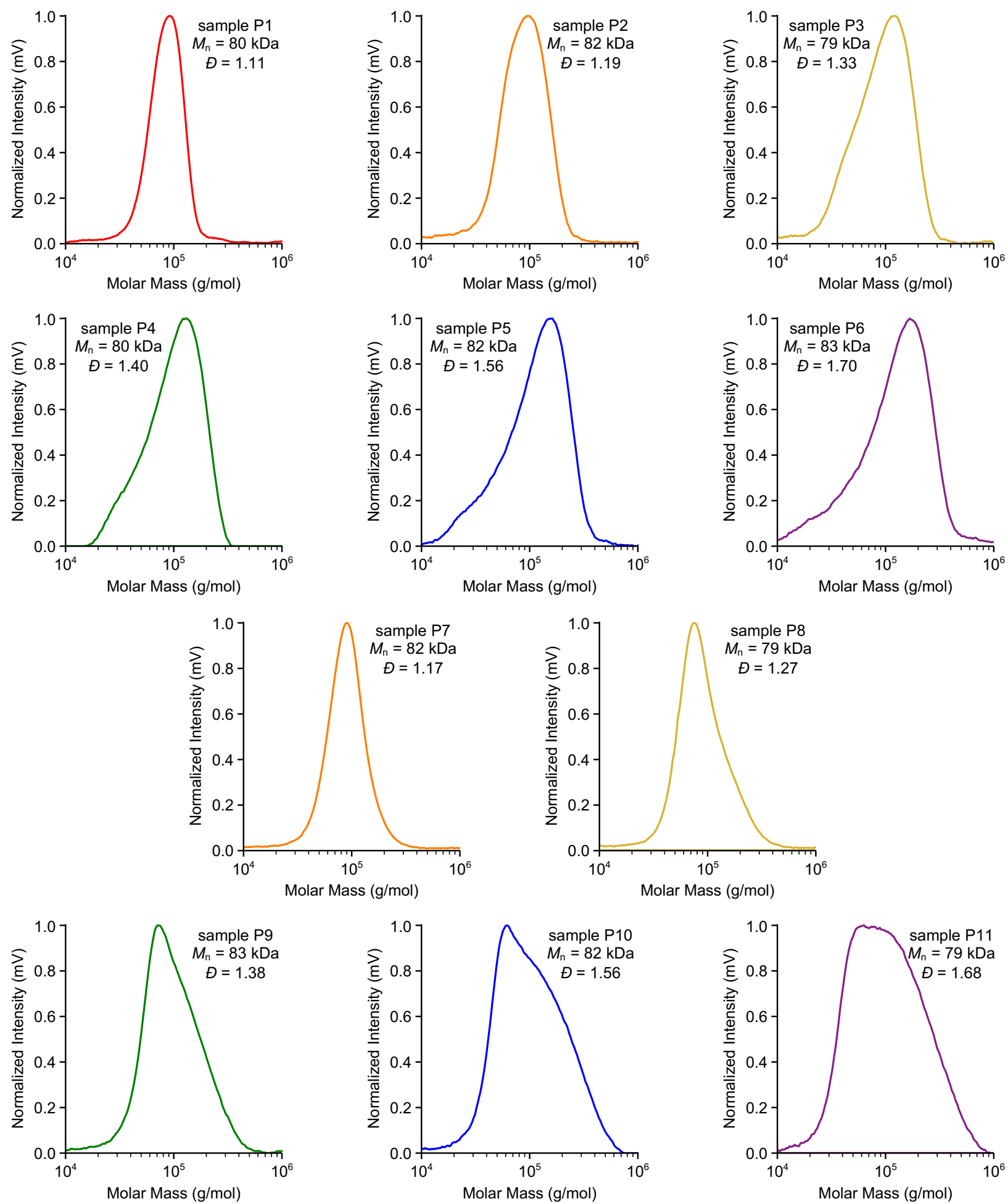

Figure S5. Molar mass distribution plots of the polymer samples in Figure 2 determined in 1,2,4trichlorobenzene at $150{ }^{\circ} \mathrm{C}$ calibrated with polyethylene standards. 

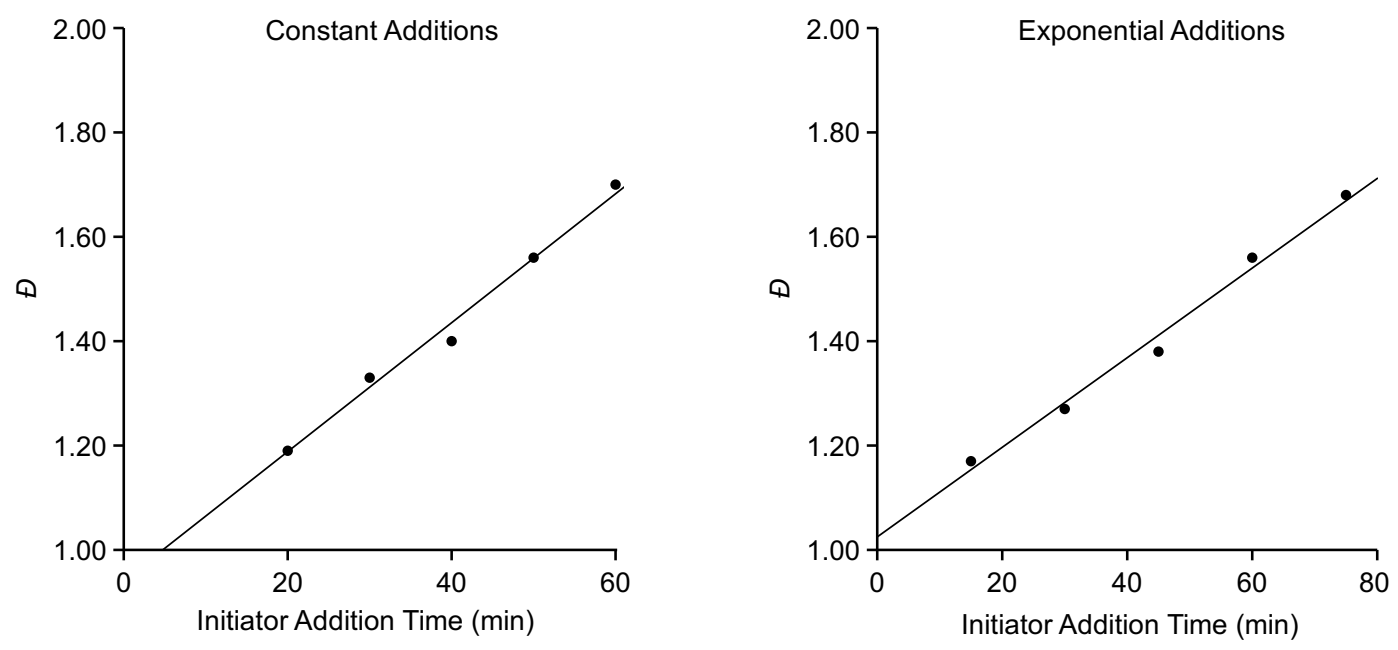

Figure S6. Linear relationship between increasing initiator addition time and polymer dispersity $(Đ)$. Polymers synthesized with constant (left) and exponential (right) addition rates.

\section{Calculation of Asymmetry Factors and Skewness}

Table S3. Asymmetry factor $\left(A_{\mathrm{s}}\right)$ and skewness $\left(\alpha_{3}\right)$ values for the polymer samples in Figure 2. See Figure $\mathrm{S} 7$ for $A_{\mathrm{s}}$ calculation details.

\begin{tabular}{ccc}
\hline Polymer Sample & $A_{\mathrm{s}}$ & $\alpha_{3}$ \\
\hline P1 & 1.50 & 0.93 \\
P2 & 1.38 & 1.14 \\
P3 & 2.07 & 1.27 \\
P4 & 2.38 & 1.20 \\
P5 & 2.77 & 1.33 \\
P6 & 2.61 & 1.39 \\
P7 & 0.78 & 1.60 \\
P8 & 0.63 & 2.47 \\
P9 & 0.55 & 2.54 \\
P10 & 0.43 & 2.84 \\
P11 & 0.49 & 3.13
\end{tabular}


Skewness was calculated using equation 1 , according to the method described by Rudin. ${ }^{2}$

\section{Equation 1:}

$$
\alpha_{3}=\frac{M_{\mathrm{z}} M_{\mathrm{w}} M_{\mathrm{n}}-3 M_{\mathrm{n}}^{2} M_{\mathrm{w}}+2 M_{\mathrm{n}}^{3}}{\left(M_{\mathrm{w}} M_{\mathrm{n}}-M_{\mathrm{n}}^{2}\right)^{3 / 2}}
$$

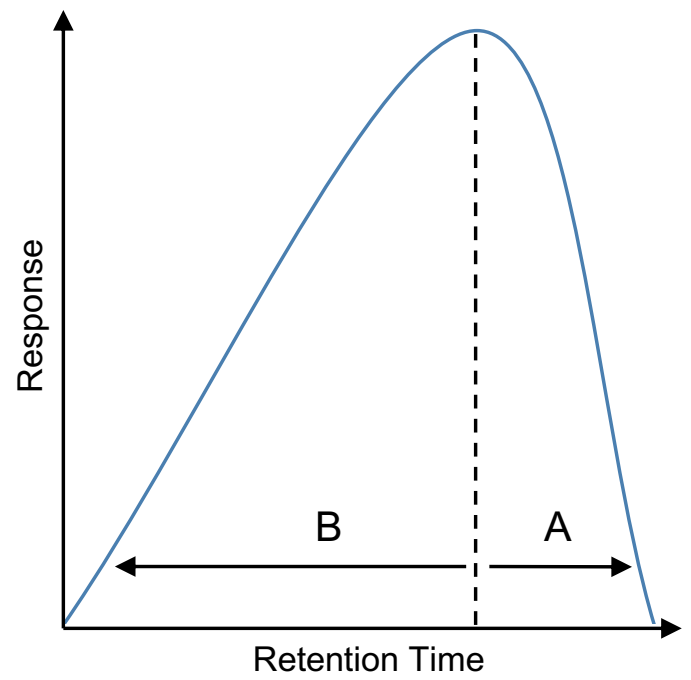

$A_{\mathrm{s}}=\mathrm{A} / \mathrm{B}$ at $10 \%$ peak height

$A_{\mathrm{s}}>1$; tailing to low molar mass

$A_{\mathrm{s}}=1$; symmetrical distribution

$A_{\mathrm{s}}<1$; tailing to high molar mass

Figure S7. Representative scheme and equation used to calculate the asymmetry factors $\left(A_{\mathrm{s}}\right)$ of GPC chromatograms for the polymer samples in Figure 2. ${ }^{3}$ 


\section{Rheological Measurements}

Rheological tests were performed on a TA Instruments DHR3 rheometer using an $8 \mathrm{~mm}$ parallel plate in a temperature controlled environmental test chamber under a nitrogen atmosphere. The sample was loaded onto the bottom parallel plate at $160^{\circ} \mathrm{C}$ and the top plate was lowered to a trim gap of $1050 \mu \mathrm{m}$. Excess polymer material was trimmed and then the plate was lowered to a gap of $1000 \mu \mathrm{m}$. Strain sweeps $(0.1-100 \%)$ at $160{ }^{\circ} \mathrm{C}$ were first performed at $0.063,0.63,6.3$, and $63 \mathrm{rad} / \mathrm{s}(0.01,0.1,1$, and $10 \mathrm{~Hz}$ respectively) to determine the linear viscoelastic region. A 5\% strain was selected as it consistently lied within the linear viscoelastic region for the preceding range of frequencies. Complex viscosity $\left(\eta^{*}\right)$ profiles were obtained at $160{ }^{\circ} \mathrm{C}$ and $5 \%$ strain with oscillatory shear from 0.1 to $500 \mathrm{rad} / \mathrm{s}$. Before each frequency sweep, the sample was equilibrated at $160{ }^{\circ} \mathrm{C}$ for $5 \mathrm{~min}$ to ensure uniform sample temperature. Each sample was tested three times and the average values are reported (Figure S8 and Figure S9).
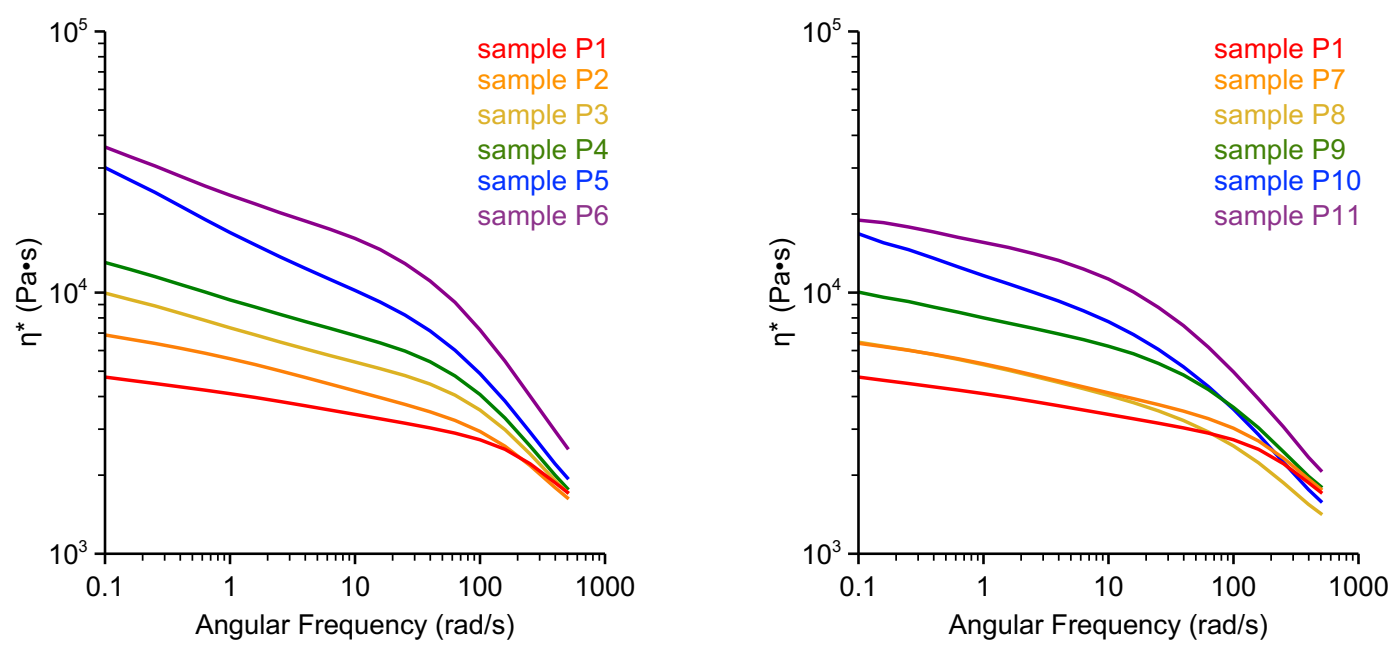

Figure S8. Complex viscosity frequency sweeps of the polymers in Figure 2, samples made with constant (left) and exponential (right) addition rates. The samples were tested at $160{ }^{\circ} \mathrm{C}$ with a $5 \%$ strain. 

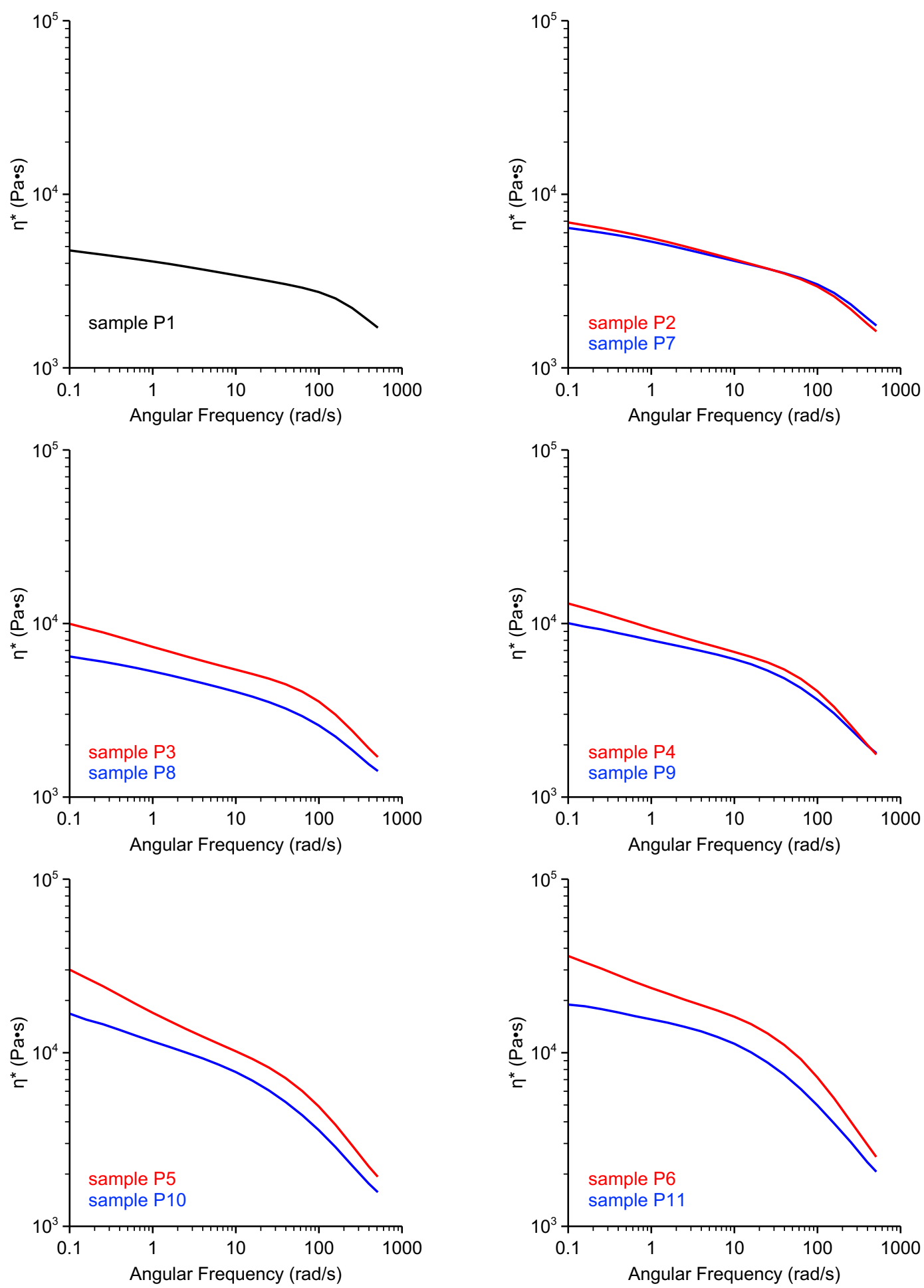

Figure S9. Complex viscosity frequency sweeps of the polymer samples in Figure 2 with similar $Ð$, but opposite tailing. The average of 3 tests (Figure S10) is plotted. Constant (red trace) and exponential (blue trace) addition rates. The samples were tested at $160{ }^{\circ} \mathrm{C}$ with a $5 \%$ strain. 

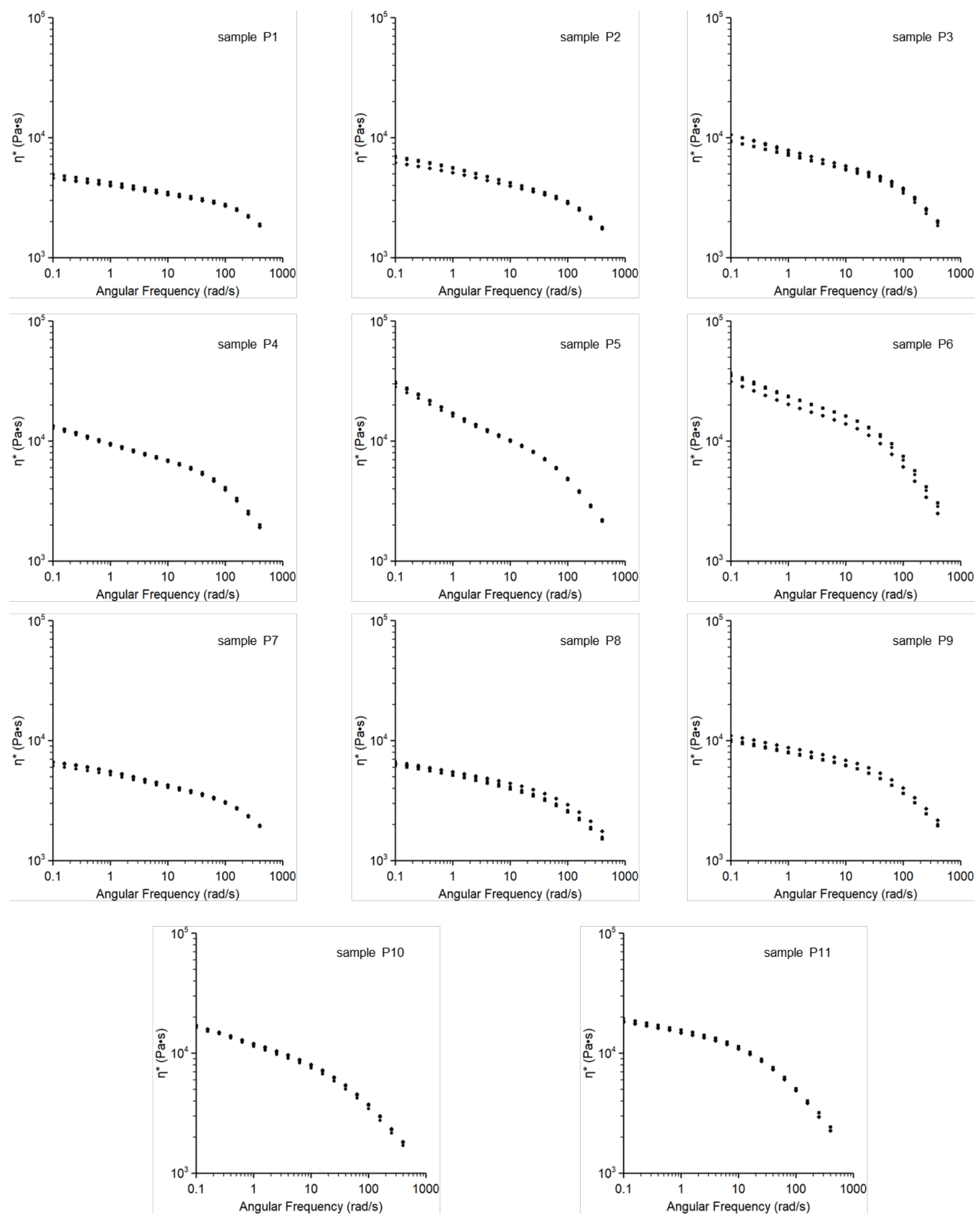

Figure S10. Triplicate tests of complex viscosity frequency sweeps for the polymer samples in Figure 2. Circles (test 1), squares (test 2), diamonds (test 3). The samples were tested at $160{ }^{\circ} \mathrm{C}$ with a $5 \%$ strain. 


\section{Uniaxial Tensile Tests}

\section{Sample Preparation}

The polyethylene sample was loaded into a stainless-steel dogbone mold (gauge length $=10$ $\mathrm{mm}$, gauge width $=2.6 \mathrm{~mm}$, gauge thickness $=0.6 \mathrm{~mm}$ ) and pressed on a Carver press hot plate under $\sim 9 \mathrm{MPa}$ at $160{ }^{\circ} \mathrm{C}$ for 15 minutes. While maintaining this pressure, the sample was cooled using water circulation $\left(\sim 10^{\circ} \mathrm{C} / \mathrm{min}\right)$. The sample was removed and trimmed with a razor blade.

\section{Mechanical Testing}

Mechanical studies were performed using a Shimadzu Autograph AGS-X tensile tester elongated with a crosshead velocity of $10 \mathrm{~mm} / \mathrm{min}$. Tensile bars were elongated until break, and at least five tensile bars were tested for each polyethylene sample. Results were analyzed using TrapeziumX v. 1.5.1 software. Representative traces are presented in Figure S11 and Figure S12.
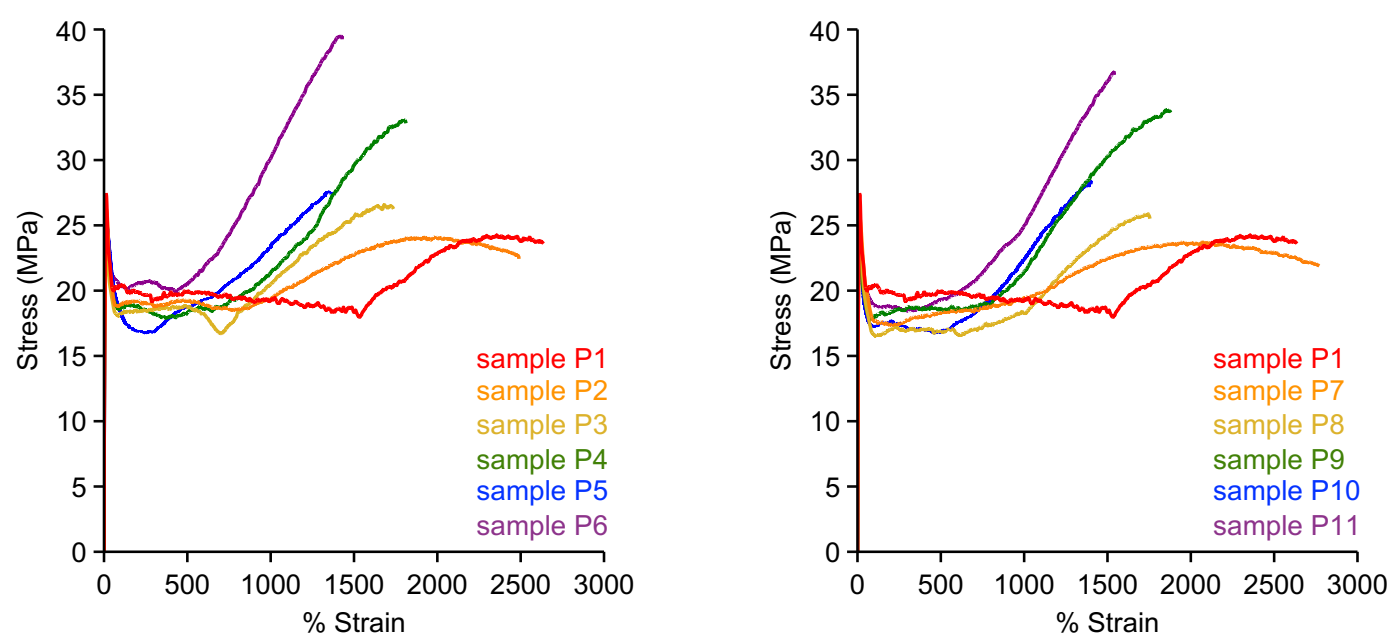

Figure S11. Representative stress vs. strain plots for the polymers in Figure 2, samples made with constant (left) and exponential (right) addition rates. The samples were tested under ambient conditions at a rate of $100 \%$ strain $/ \mathrm{min}$. 

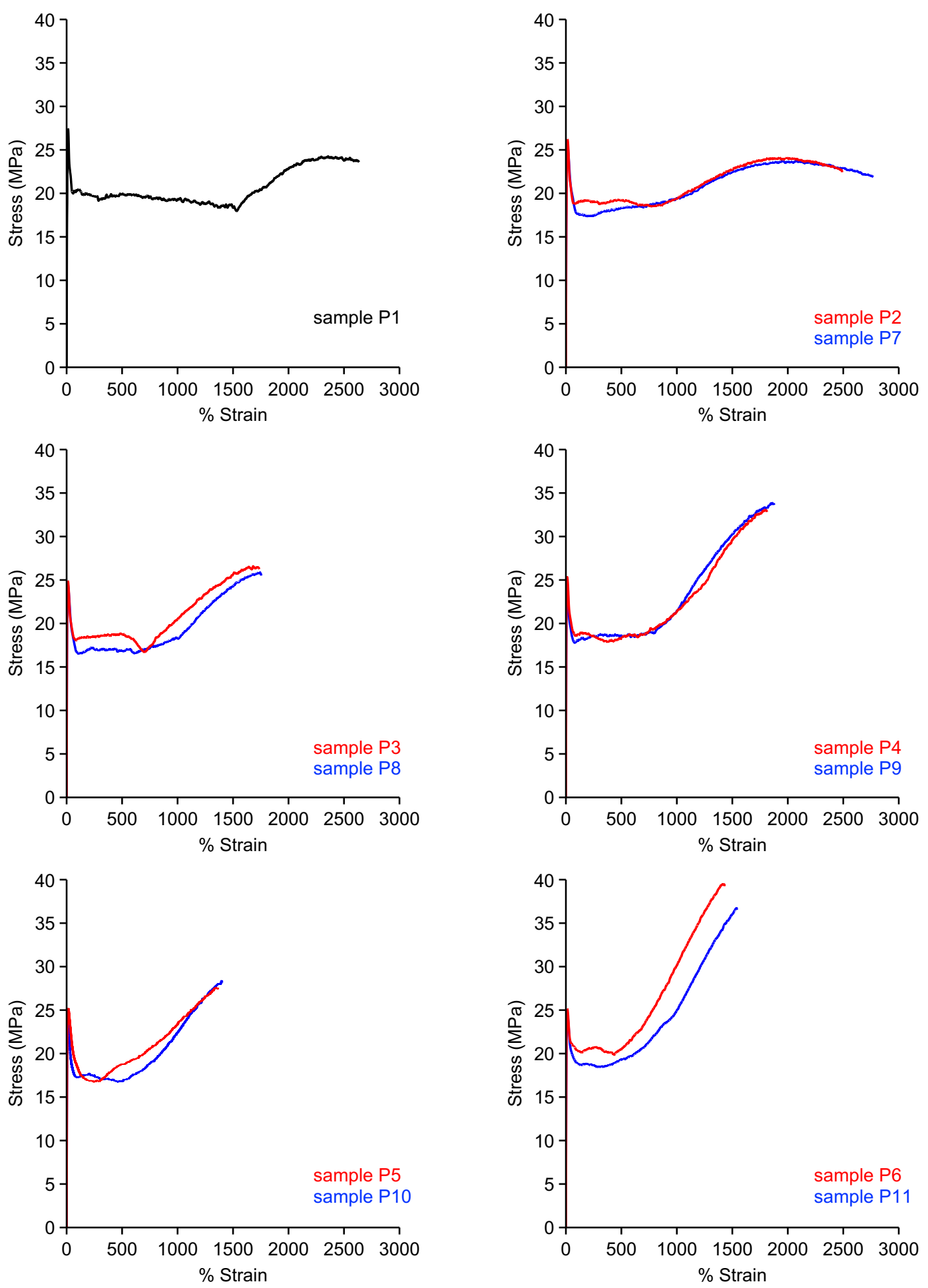

Figure S12. Representative stress vs. strain plots for the polymer samples in Figure 2 with similar $Ð$, but opposite tailing. Samples made with constant (red trace) and exponential (blue trace) addition rates. The samples were tested under ambient conditions at a rate of $100 \%$ strain $/ \mathrm{min}$. 

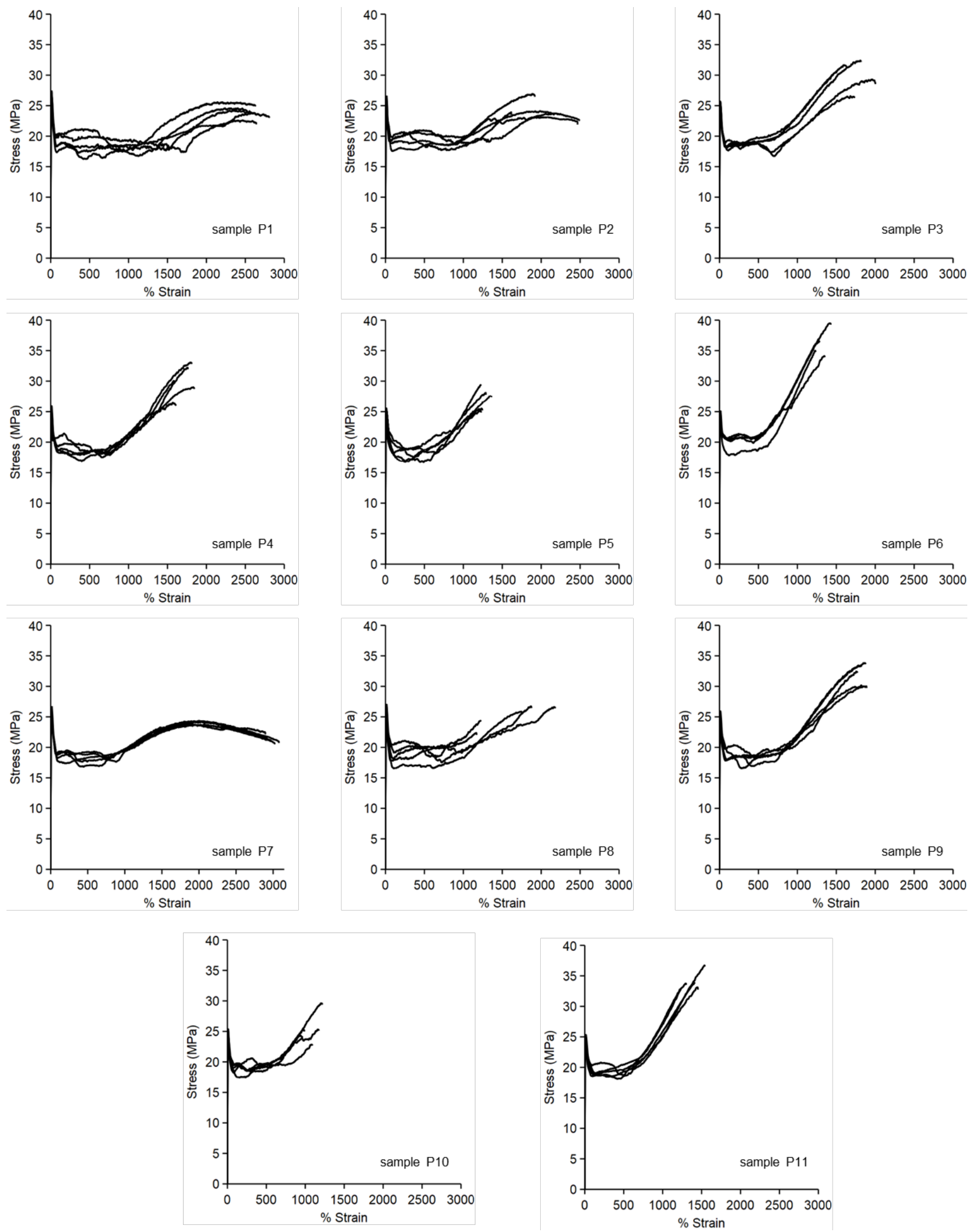

Figure S13. All tensile data for samples P1-P11. Tensile tests were repeated 5 times under ambient conditions at a rate of $100 \% \mathrm{strain} / \mathrm{min}$. 


\section{References}

(1) Mason, A. F.; Tian, J.; Hustad, P. D.; Lobkosky, E. B.; Coates, G. W. Syndiospecific Living Catalysts for Propylene Polymerization: Effect of Fluorination on Activity, Stereoselectivity, and Termination. Isr. J. Chem. 2003, 42, 301-306.

(2) Rudin, A. Molecular Weight Distributions of Polymers. J. Chem. Educ. 1969, 46, 595600.

(3) Kirkland, J. J.; Yau, W. W.; Stoklosa, H. J.; Dilks, C. H. Sampling and Extra-Column Effects in High-Performance Liquid Chromatography: Influence of Peak Skew on Plate Count Calculations. J. Chromatogr. Sci. 1977, 15, 303-316. 